\title{
Dengue Virus Serotype-2 Impairs Proliferation of Healthy Donors' T Lymphocytes
}

\author{
C.J.Fuentes-Miranda ${ }^{a} \quad$ F.J. Sánchez-García ${ }^{a} \quad$ A.R. Coker ${ }^{b} \quad$ O. Rojas-Espinosa ${ }^{a}$ \\ R. Salinas-Tobón ${ }^{a}$ M.M.B. Moreno-Altamirano ${ }^{a}$ \\ a Departamento de Inmunología, Escuela Nacional de Ciencias Biológicas, Instituto Politécnico Nacional, México D.F., \\ México; ${ }^{\mathrm{b} C e n t e r}$ for Amyloidosis and Acute Phase Proteins, Division of Medicine, Royal Free Campus, University College \\ London, London, UK
}

\section{Key Words}

T lymphocytes $\cdot$ Dengue virus $\cdot$ Cell proliferation $\cdot$ NF-AT . $\mathrm{NF}-\mathrm{KB} \cdot$ Intracellular $\mathrm{Ca}^{2+}$

\begin{abstract}
Objectives: T lymphocytes are not infected by dengue virus (DENV), nevertheless it is possible that exposure to DENV may affect their function. T lymphocytes from DENV-infected individuals are impaired in their proliferative capacity, although this effect has been attributed to altered function of antigen-presenting cells rather than to an intrinsic defect on $\mathrm{T}$ lymphocytes. Here we analyzed whether T lymphocytes from healthy donors became impaired in their proliferative capacity following in vitro exposure to DENV serotype-2 (DENV-2), as well as the possible mechanisms for this. Methods: Isolated CD4+ and CD8+ T lymphocytes from healthy donors were in vitro exposed to DENV-2, before polyclonal activation, cell proliferation, IL-2 synthesis. IL-2Ra expression, nuclear translocation of NF-AT and NF-KB, and intracellular calcium flux were assessed. Results: In vitro exposure of both CD4+ and CD8+ T lymphocytes from healthy donors to DENV-2 impairs cell proliferation, IL-2 synthesis, and IL-2Ra (CD25) cell membrane expression. Signalling wise, exposure to DENV-2 impairs the nuclear translocation of NF-AT, downstream of intracellular calcium mobilization, as well as that
\end{abstract}

of NF-KB. Conclusion: In the course of a dengue infection, direct exposure of T lymphocytes to DENV could affect cellmediated immune responses.

(c) 2014 S. Karger AG, Basel

\section{Introduction}

Dengue is caused by any of the four dengue virus (DENV) serotypes - 1, 2, 3 or 4 . The World Health Organization estimates that these viruses cause 100-500 million infections each year in over 100 countries, resulting in 20,000 deaths annually [1]. The more severe forms of this viral infection are dengue hemorrhagic fever (DHF) and dengue shock syndrome (DSS) $[2,3]$. The mechanisms that lead to these clinical outcomes are unknown, however there is growing evidence that the pathophysiology of dengue is mediated by host immune response [2, 4]. Several lines of evidence indicate that anti-dengue antibodies [5-7], cytokines [8-10], soluble immune mediators [11-13] and cross-reactive memory $\mathrm{T}$ lymphocytes [14-16], along with high dengue viral loads [17], contribute to the progression to DHF/DSS and death $[18,19]$.

$\mathrm{T}$ lymphocytes play both effector and regulatory roles in the innate and adaptive immune responses, and several studies have shown that $\mathrm{T}$ lymphocytes are involved in the development of DHF/DSS [20]. In particular, cross-

\section{KARGER}

E-Mail karger@karger.com

www.karger.com/int (c) 2014 S. Karger AG, Basel

$0300-5526 / 14 / 0572-0083 \$ 39.50 / 0$
M. Maximina Bertha Moreno-Altamirano, $\mathrm{PhD}$

Departamento de Inmunología

Escuela Nacional de Ciencias Biológicas, Instituto Politécnico Nacional Carpio y Plan de Ayala, Col. Sto. Tomás, México DF 11340 (Mexico)

E-Mail morsan846698716@aol.com 
reactive memory $\mathrm{T}$ lymphocytes have been associated with changes in the vasculature, leading to vascular leakage [21-23], and activation of $\mathrm{T}$ lymphocytes during viremia, which is more evident in DHF, is reflected in the overproduction of cytokines [24]. Furthermore, CD4+ and CD8+ T-lymphocyte clones that proliferate in response to DENV antigens in a serotype cross-reactive fashion have been isolated from dengue patients [25-27], thus suggesting that dengue serotype cross-reactive T lymphocytes may contribute to dengue pathogenesis.

On the other hand, the role of activated Tlymphocytes in the pathology of DENV infection contrasts with the observed drop in the absolute numbers of T lymphocytes during the acute phase of DENV infection [28, 29]. For example, a study that compared the cellular immune status of patients with DHF, dengue fever, and non-dengue viral infections showed a reduction of total $\mathrm{CD} 3+, \mathrm{CD} 4+$ and CD8+ Tlymphocytes in DHF but not in the other two groups [30]. In addition, $\mathrm{T}$ lymphocytes isolated from acute DENV-infected patients are impaired in their proliferative response to in vitro mitogenic stimulation [31].

Several cell types have been identified as targets for DENV [32], mainly monocytes [33, 34], macrophages $[35,36]$, dendritic cells [37, 38], Langerhans' cells [39], and B cells [40]. Attempts to determine if DENV infects $\mathrm{T}$ lymphocytes have been made and results have been contradictory [41-43].

Here we have analyzed the consequences of the in vitro exposure of T lymphocytes isolated from healthy donors to DENV-2. We found that DENV-2 reduces the proliferative capacity of $\mathrm{T}$ lymphocytes in response to concanavalin A (ConA), by impairing the activation of NF-AT, and NF- $\kappa B$. Impairment of these two transcription factors correlated with lower IL-2 synthesis and lower IL-2R $\alpha$ expression by T lymphocytes. Activation-induced calcium influx was not impaired. Together these findings suggest that DENV-2 directly inhibits T-lymphocyte activation by interfering with cell activation pathways downstream of calcium mobilization and that alterations in cell-mediated immunity during the course of DENV infections cannot be exclusively attributed to the 'classical' DENV cell targets, i.e. monocytes and dendritic cells.

\section{Materials and Methods}

Dengue Virus

DENV-2, strain New Guinea, was a kind gift of InDRE (Mexico). Virus was propagated in Aedes albopictus C6/36 cells. When cell cultures reached about $80 \%$ of the cytopathic effect, cells were lysed by freezing and thawing and, after centrifugation at $4,000 \mathrm{~g}$ for $10 \mathrm{~min}$, the supernatants were collected. DENV-2 was purified by centrifugation of $2 \mathrm{vol}(8 \mathrm{ml} /$ tube) of supernatant over $1 \mathrm{vol}$ ( $4 \mathrm{ml} /$ tube) of $30 \%$ sucrose in PBS at 38,000 rpm in a SW40Ti rotor (Beckman) for $3.5 \mathrm{~h}$. The DENV-2-containing pellet was recovered and washed with PBS by centrifugation at $38,000 \mathrm{rpm}$ in a SW40Ti rotor for $1 \mathrm{~h}$. Viral titer was assessed by the cytopathic effect on Vero cells and expressed as plaque-forming units $/ \mathrm{ml}(\mathrm{pfu} / \mathrm{ml})$. The titer of DENV-2 stock was adjusted to $1.5 \times 10^{6} \mathrm{pfu} / \mathrm{ml}$.

\section{Cell Isolation and Cell Proliferation}

Peripheral blood mononuclear cells were obtained by differential centrifugation over Ficoll-Paque (Invitrogen) from buffy coats from healthy donors. CD3+, CD4+ and CD8+ T lymphocytes were purified by a magnetic-based negative selection approach (human pan T-cell isolation kit II, CD4+ T-cell isolation kit II, and human CD8+ T-cell isolation kit II, respectively, from Miltenyi Biotec). CD4+ and CD8+ T-lymphocyte purity was assessed by flow cytometry by using FITC-labelled anti-human CD4, FITC-labelled anti-human CD8, and PerCP-labelled anti-human CD3 (BD Biosciences). T-cell proliferation in response to ConA (Sigma) was assessed in carboxyfluorescein diacetate succinimidyl ester (CFSE) (Invitrogen) loaded cells stimulated with ConA ( $5 \mu \mathrm{g} / \mathrm{ml})$. Briefly, prior to stimulation, $1 \times 10^{7}$ cells $/ \mathrm{ml}$ were incubated in $5 \mu \mathrm{M}$ CFSE for $8 \mathrm{~min}$ at $37^{\circ}$, after which the excess of CFSE was quenched by adding an equal volume of FBS for $5 \mathrm{~min}$. Cells were washed, adjusted to a cell concentration of $1 \times 10^{6} / \mathrm{ml}$, stimulated, and then cultured in serum-free AIM-V medium in U-bottomed 96-well culture plates (Corning). In order to assess the effect of DENV-2 on T-cell proliferation, T lymphocytes were incubated in the presence of DENV-2 at a multiplicity of infection (MOI) of 10 for $2 \mathrm{~h}$ before the addition of ConA. Cells were incubated at $37^{\circ}$ for 5 days and the diminution of CFSE mean fluorescent intensity, as indicative of cell proliferation, was analyzed by flow cytometry. Results are expressed as the percentage of cells with low CFSE mean fluorescent intensity.

\section{IL-2 Synthesis}

The amount of IL-2 was assessed in the culture supernatants of $24 \mathrm{~h}$ activated CD $3+$ T lymphocytes by ELISA. Briefly, $1 \times 10^{6}$ cells/ $\mathrm{ml} /$ well in 12-well plates were (a) left unstimulated, (b) incubated in the presence of DENV-2, (c) preincubated with DENV-2 and then stimulated with $5 \mu \mathrm{g} / \mathrm{ml}$ of ConA, or (d) stimulated with $5 \mu \mathrm{g} /$ $\mathrm{ml}$ of ConA alone. After $24 \mathrm{~h}$ of incubation at $37^{\circ}, 100 \mu \mathrm{l}$ of the culture supernatants (in triplicate) were collected and diluted 1:2 in carbonate buffer $\left(15 \mathrm{mM} \mathrm{Na}_{2} \mathrm{CO}_{3}, 35 \mathrm{mM} \mathrm{NaHCO}, 0.2 \mathrm{~g} / \mathrm{l}\right.$ $\mathrm{NaN}_{3}, \mathrm{pH}$ 9.6), transferred to MaxiSorb ELISA plates (Nunc) and incubated overnight at $37^{\circ}$. Next, the plates were washed 3 times with $0.5 \%$ Tween-20 in PBS (PBS-T) blocked with 3\% non-fat powder milk in PBS-T for $1 \mathrm{~h}$ at $37^{\circ}$, and then incubated with $1 \mu \mathrm{g} /$ $\mathrm{ml}$ of anti-IL-2 monoclonal antibody $(200 \mu \mathrm{l} /$ well $)$ (Sigma) for $2 \mathrm{~h}$. The plates were then washed with PBS-T and $200 \mu \mathrm{l}$ of PO-labelled secondary antibody $(1 \mu \mathrm{g} / \mathrm{ml})$ was added. Plates were further incubated for $2 \mathrm{~h}$, washed 3 times with PBS-T, and finally $100 \mu \mathrm{l}$ of freshly prepared peroxidase substrate (Sigma) was added. After $30 \mathrm{~min}$, the enzymatic reaction was stopped by adding $30 \mu \mathrm{l}$ of $12 \mathrm{~N}$ $\mathrm{H}_{2} \mathrm{SO}_{4}$. The optical density, indicative of the amount of IL-2 in the supernatants, was read at $492 \mathrm{~nm}$ in an ELISA plate reader (Lab Systems). 


\section{$I L-2 R \alpha$ Expression}

Expression of IL-2Ra (CD25) was evaluated by flow cytometry. CD3+ T lymphocytes were (a) left unstimulated, (b) incubated in the presence of DENV-2, (c) preincubated with DENV-2 and then stimulated with $1 \mathrm{ng} / \mathrm{ml} \mathrm{PMA}+200 \mathrm{ng} / \mathrm{ml}$ ionomycin, or (d) $1 \mathrm{ng} /$ $\mathrm{ml} \mathrm{PMA}+200 \mathrm{ng} / \mathrm{ml}$ ionomycin. $48 \mathrm{~h}$ after mitogen stimulation, the cells were harvested, washed with PBS, and simultaneously stained with PE-conjugated anti-human CD25 moAb (BD Biosciences) $(1 \mu \mathrm{g} / \mathrm{ml})$ and with PerCP-conjugated anti-human CD3 (BD Biosciences) $(1 \mu \mathrm{g} / \mathrm{ml})$ at $4^{\circ}$ for $30 \mathrm{~min}$. The cells were then washed with $0.01 \%$ BSA, $0.01 \% \mathrm{NaN}_{3}$ in PBS and analyzed by flow cytometry (Becton-Dickinson). The results are expressed as the percentage of CD25+ cells in the CD3+ population.

\section{Transcription Factor Activation Assays}

Nuclear translocation of NF-AT and p65 NF- $\kappa$ B was assessed by confocal microscopy (LSM5 Pascal; Zeiss), for which CD4+ and CD8+ T lymphocytes were independently incubated in the presence of DENV-2 at a MOI of 10 for $2 \mathrm{~h}$ and then with ConA for $16 \mathrm{~h}$, when indicated. Cells were then fixed and permeabilized (Cytofix/Cytoperm; BD Biosciences) and stained with anti-NF-AT moAb (Santa Cruz Biotechnology) or anti-p65 NF- $\kappa$ B rabbit polyclonal antibody (Santa Cruz Biotechnology) at a final concentration of $1 \mu \mathrm{g} / \mathrm{ml}$, followed by FITC-labelled secondary antibody. Cells were spun down on glass slips by using a cytospin and then mounted with DAPI-containing Vectashield (Vector) and analyzed. The percentage of cells showing nuclear translocation of NF-AT or NF- $\kappa$ B was calculated from several microscopic fields from two independent experiments.

\section{Calcium Flux}

CD3+ T lymphocytes $\left(1 \times 10^{7} / \mathrm{ml}\right)$ were loaded with Fluo-4 (Invitrogen) at a concentration of $3 \mu \mathrm{M}$ for $30 \mathrm{~min}$ at $37^{\circ}$. After washing with PBS the cells were adjusted at a concentration of $1 \times$ $10^{6}$ cells $/ \mathrm{ml}$ in RPMI-1640 medium supplemented with $2 \mathrm{mM}$ $\mathrm{CaCl}_{2}$. Mean fluorescent intensity was measured by flow cytometry (FACScan; Becton-Dickinson) and recorded over $30 \mathrm{~s}$ (base level) and then ConA at a final concentration of $5 \mu \mathrm{g} / \mathrm{ml}$ was added and the mean fluorescent intensity (as indicative of intracellular calcium concentration) was recorded over a period of approximately $400 \mathrm{~s}$. Raw data (CellQuest software; BD Biosciences) was analyzed by FlowJo version 8.7 software (Tree Star, Inc.).

\section{DENV-2 Virus Attachment to T Lymphocytes}

In order to assess DENV-2 virus interaction with T lymphocytes, freshly isolated T lymphocytes were cultured in serum-free AIM-V medium in the presence of DENV-2 at a MOI of 1 for $30 \mathrm{~min}, 60 \mathrm{~min}, 1 \mathrm{~h}$, and $2 \mathrm{~h}$. Cells were fixed with $1 \%$ paraformaldehyde and then stained with anti-E (DENV envelope protein) mouse moAb (Santa Cruz Biotechnology) $(0.5 \mu \mathrm{g} / \mathrm{ml}$ in $1 \%$ powdered milk-PBS), followed by anti-mouse IgG-FITC (Santa Cruz Biotechnology). T lymphocytes with no DENV-2, stained under the same protocol, were used as a negative control. Cells were mounted in DAPI-Vectashield (Vector) and observed in a LSM5 Pascal confocal microscope (Zeiss). A 2-hour incubation with DENV-2 proved to be the optimal time to analyze virus attachment to T lymphocytes. In addition, in order to quantify DENV-2 attachment to $\mathrm{T}$ lymphocytes, fixed cells treated as described were analyzed by flow cytometry (BD Biosciences). In the latter case, the percentage of CD3+ cells that harbor DENV-2 envelope (E) pro- tein was assessed by dual staining, i.e. anti-E moAb, followed by anti-mouse IgG-FITC + anti-CD3-PE. Data was analyzed using CellQuest software (BD Biosciences).

ConA Binding to T Lymphocytes

Purified T lymphocytes were incubated in the presence of DENV2 for $2 \mathrm{~h}$ at $37^{\circ}$ in $5 \% \mathrm{CO}_{2}$ atmosphere. After this, cells were washed with PBS or left unwashed and labelled with ConA-biotin $(5 \mu \mathrm{g} / \mathrm{ml})$ (Sigma) for $40 \mathrm{~min}$ followed by Streptavidin-FITC (Sigma) for 60 min with a washing step in between. Finally, cells were washed with PBS and fixed with $4 \%$ paraformaldehyde in PBS. The percentage of ConA-labelled cells was assessed by flow cytometry (BD Biosciences) and analyzed using CellQuest software (BD Biosciences).

\section{Results}

\section{CD4+ and CD8+ T Lymphocytes Are Susceptible to} DENV-2-Dependent Inhibition of ConA-Induced Cell Proliferation

CD4+ and CD8+ T lymphocytes were independently isolated from the same blood donors. Cell proliferation was quantified after 5 days in culture. Figure 1a shows that $\mathrm{T}$ lymphocytes incubated in medium alone or in the presence of DENV-2 did not proliferate, whereas stimulation with ConA induced a significant cell proliferation. A 2-hour incubation of Tlymphocytes with DENV-2 before mitogen addition diminished the cell proliferation as compared to cells treated with the mitogen in the absence of DENV-2. These experiments show that both CD4+ and CD8+ T lymphocytes are impaired in their proliferation capacity if they were previously exposed to DENV-2. Figure $2 \mathrm{~b}$ shows a representative example of the purity of CD4+ and CD8+ T lymphocytes used for these experiments.

\section{DENV-2 Inhibits the Synthesis of IL-2 in Mitogen-}

\section{Stimulated T Lymphocytes}

IL-2 synthesis is a hallmark of T-cell activation and plays an important role in T-cell proliferation. It has been previously shown that several viruses such as human herpesvirus 6 and hepatitis C inhibit IL-2 synthesis and T-lymphocyte proliferation $[44,45]$. In order to explore if a similar mechanism is at play in $\mathrm{T}$ lymphocytes exposed to DENV-2, we evaluated the production of IL-2 in the supernatants of mitogen-activated $\mathrm{T}$ lymphocytes as well as in T lymphocytes exposed to DENV-2 prior to mitogen stimulation. Figure 2 shows that the synthesis of IL-2 was impaired in T lymphocytes exposed to DENV-2 before ConA stimulation as compared with the synthesis of IL-2 in T lymphocytes stimulated with ConA in the absence of DENV-2. 


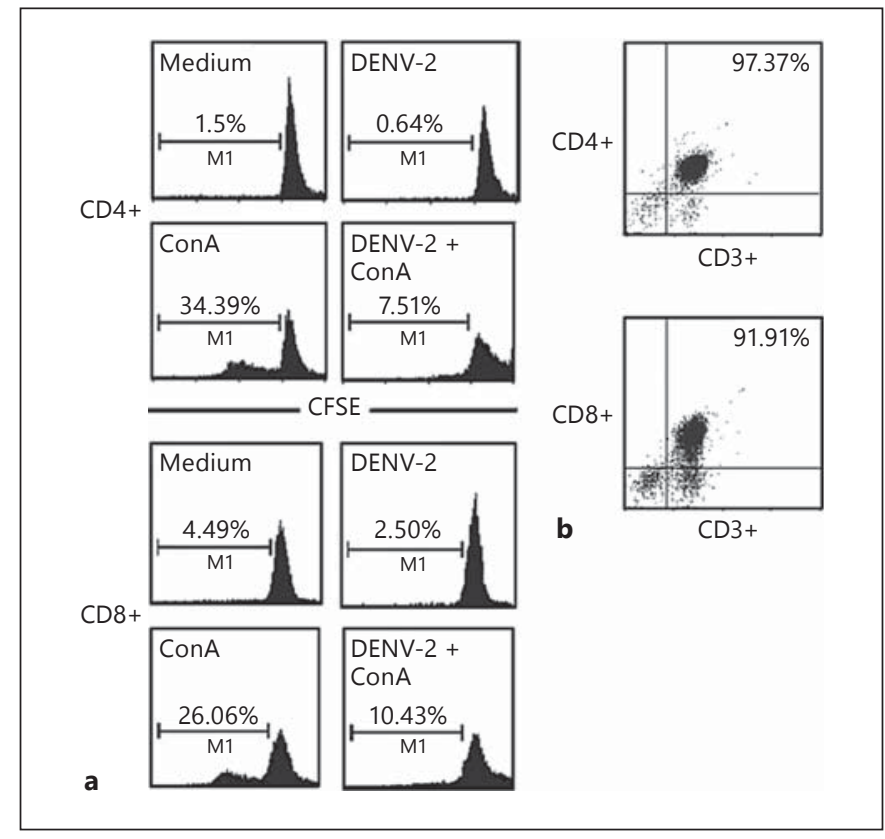

Fig. 1. CD4+ and CD8+ T lymphocytes are susceptible to DENV2-dependent inhibition of ConA-induced cell proliferation. CD4+ and CD8+ T lymphocytes were independently isolated from the same blood donors. T lymphocytes were labelled with CFSE and then split into four culture conditions: medium alone, ConA, DENV-2, and DENV-2 for $2 \mathrm{~h}$ and then ConA. Cells were incubated at $37^{\circ}$ for 5 days and the CFSE dilution (cell proliferation) was assessed by flow cytometry. a Representative CFSE dilution profile for CD4+ and CD8+ T-lymphocyte proliferation. b Purity of CD3+ CD4+, and CD3+ CD8+ T lymphocytes. Results are representative of three independent experiments.

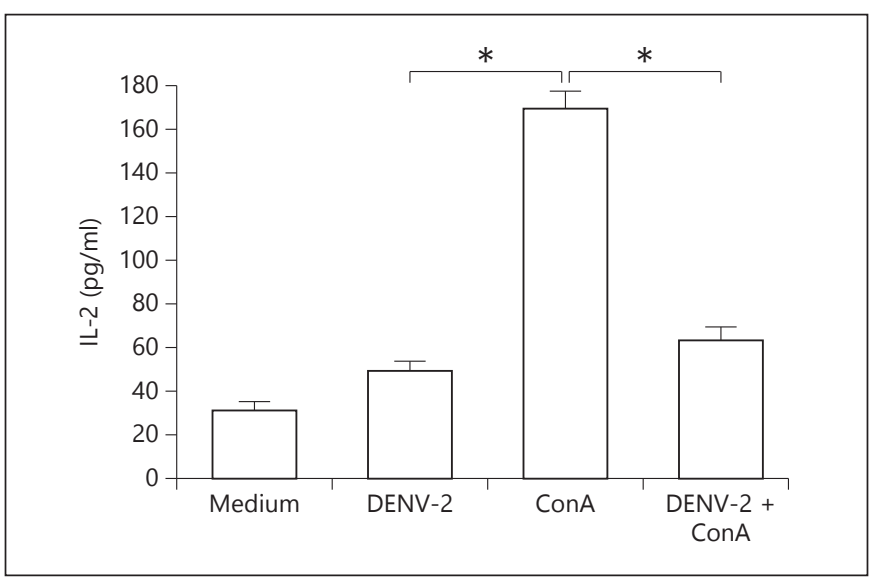

Fig. 2. DENV-2 impairs ConA-induced synthesis of IL-2 by T lymphocytes. T lymphocytes were cultured at $37^{\circ}$ for $24 \mathrm{~h}$ in the presence of medium alone, DENV-2 from C6/36 supernatant, ConA or DENV$2+$ ConA. After this time, cell supernatants were harvested and assayed for IL- 2 content. Results are expressed as $\mathrm{pg} / \mathrm{ml} \pm \mathrm{SD}$. Four independent experiments were carried out. ${ }^{*} \mathrm{p}<0.01$ (Student's t test).
DENV-2 Inhibits the Expression of IL-2R $\alpha$

Concomitant to the synthesis of IL-2, activated T lymphocytes express the IL-2Ra receptor (CD25) on their cell membrane, thus engaging themselves in a feedback loop of cell activation and proliferation [46]. Therefore, we wanted to evaluate if DENV-2 is able to interfere with this process. In preliminary experiments (data not shown) we observed that PMA/ionomycin performs better than ConA for IL-2Ra expression. Figure 3 shows that DENV2 interferes with IL-2Ra (CD25) expression in PMA/ionomycin-activated T lymphocytes. In the absence of PMA/ ionomycin, DENV-2 by itself did not induce any significant change in the expression of CD25.

\section{Activation of NF-AT and NF- $\kappa B$ Is Impaired by DENV-2}

By using a confocal microscopy approach, we evaluated the effect that the in vitro exposure of DENV-2 has on the activation status of NF-AT and NF- $\kappa \mathrm{B}$ on ConAstimulated $\mathrm{T}$ lymphocytes. As shown, the nuclear translocation of NF-AT (fig. 4a) and NF- $\kappa B$ (fig. 4b) was impaired when Tlymphocytes had been exposed to DENV2 prior to ConA stimulation.

Intracytoplasmic Calcium Fluxes in T Lymphocytes

Are Not Impaired by Pre-Exposure to DENV-2

T-cell activation is largely dependent on intracellular calcium fluxes [47] and calcium flux is a key factor for activation of NF-AT $[48,49]$. After finding that T lymphocytes that had been exposed to DENV-2 are impaired in their proliferative response to ConA, in the synthesis of IL-2, in the expression of IL-2R $\alpha$, and in the activation of NF-AT, we wondered whether these effects were due to impairment in the ability of $\mathrm{T}$ lymphocytes to mobilize calcium. Basal intracellular calcium concentration in $\mathrm{T}$ lymphocytes maintained in culture medium alone or preexposed to DENV-2 was recorded for $30 \mathrm{~s}$ and after stimulation with ConA, calcium fluxes were followed over a period of about $400 \mathrm{~s}$. Figure 5 shows that DENV-2 did not inhibit ConA-induced mobilization of intracellular calcium. Moreover, a discreet but consistent increase in intracellular calcium concentration was observed in DENV-2 pre-exposed T lymphocytes upon ConA stimulation, as compared to that in unexposed T lymphocytes. However, the time-course response was very similar in both cases.

\section{DENV-2 Attachment to T Lymphocytes}

DENV-2 attachment to T lymphocytes was assessed by staining DENV-2 envelope protein with anti-E moAb followed by FITC-labelled secondary antibody and confocal 

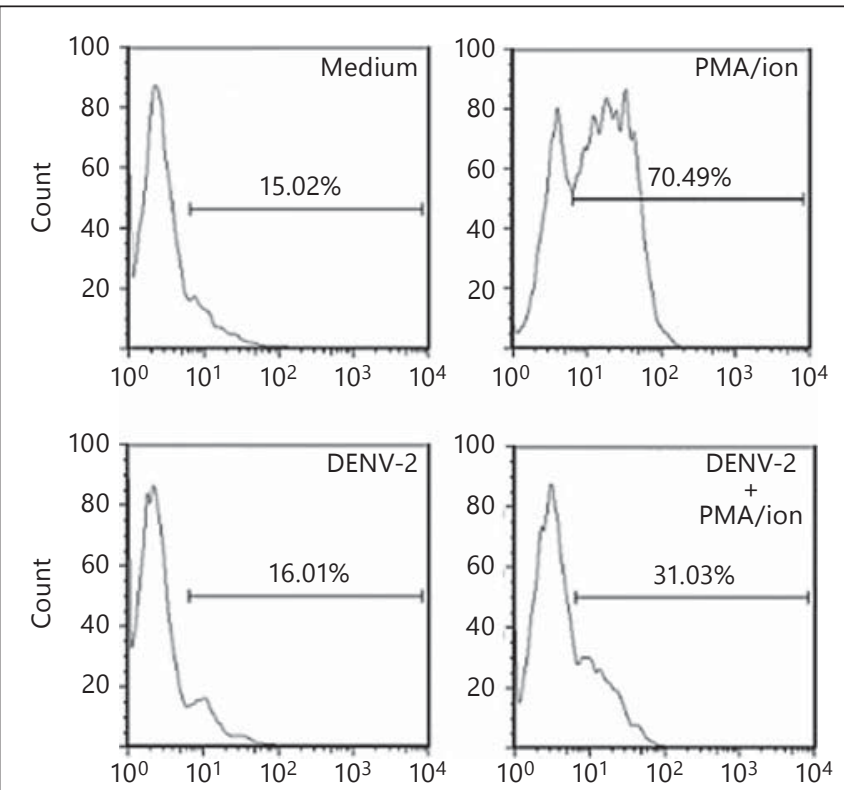

a

CD25-PE (IL-2R $\alpha)$

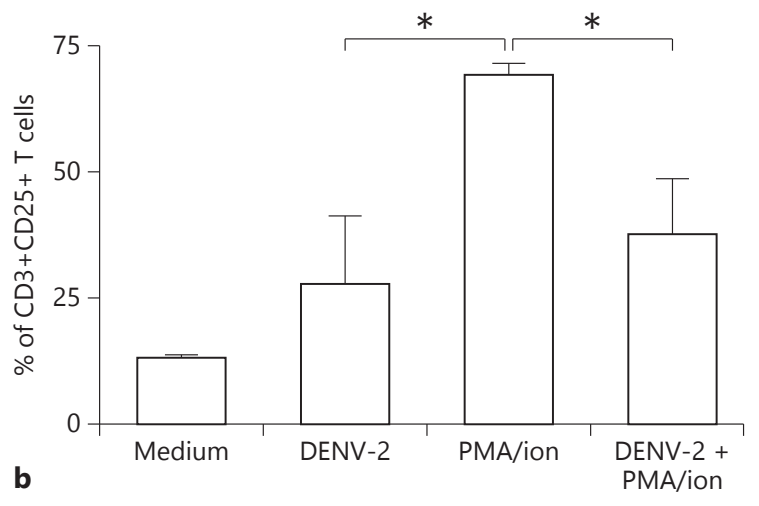

Fig. 3. DENV-2 impairs activation-induced expression of IL-2Ra (CD25) in T lymphocytes. T lymphocytes were cultured at $37^{\circ}$ for $48 \mathrm{~h}$ in the presence of medium alone, DENV-2 from C6/36 supernatant, PMA/ionomycin or DENV-2 + PMA/ionomycin. After this time, cells were harvested and stained with anti-CD3-PerCP and anti-CD25-PE monoclonal antibodies. CD25 expression on CD3+ cells was determined by flow cytometry. a Representative histograms of CD25 expression in the CD3+ cell population. b Percentage of CD25+ cells in the CD3+ population \pm SD $(n=4)$. $* \mathrm{p}<0.01$ (Student's t test).

microscopy (fig. 6a). In order to quantify DENV-2 attachment to T lymphocytes, purified T lymphocytes were exposed to DENV-2 and then double stained for CD3 and DENV-2 envelope (E) protein expression. DENV-2 does bind to the cell membrane of T lymphocytes. The percentage of CD3+ T lymphocytes harboring viral particles was only about $2 \%$, as assessed by flow cytometry (fig. 6b).
Binding of ConA to T Lymphocytes Is Not Impaired by Pre-Exposure to DENV-2

In order to test the possibility that the observed DENV2 inhibitory effects on ConA-induced T-lymphocyte activity was due to DENV-2-mediated inhibition of ConA binding to the cognate receptor of $\mathrm{T}$ lymphocytes, purified $\mathrm{T}$ lymphocytes were labelled with ConA-biotin followed by Streptavidin-FITC after appropriate culture conditions. Data showed that preincubation of T lymphocytes with DENV-2 did not inhibit binding of ConA, and that ConA binding to T lymphocytes proceeds just as well whether DENV-2 is washed away or not, previous to ConA-biotin/Streptavidin-FITC labeling (fig. 7).

\section{Discussion}

There is increasing evidence that the immune system plays a key role in determining the severity of dengue disease $[18,19]$, in particular the array of cytokines produced during infection $[8-10,24]$. The role of T lymphocytes in this process is controversial since on the one hand there is evidence that activation of T lymphocytes leads to proinflammatory cytokine synthesis [20-27] and on the other there is evidence that T-lymphocyte proliferation in dengue patients is impaired [28-31] and that patients with acute DENV infection are leukopenic $[28,29]$. Additionally, there are contradictory results as to whether T lymphocytes can be infected or not with DENV [4143]. In our hands, $T$ lymphocytes are not infected with DENV-2 (data not shown).

We show here that isolated CD4+ and CD8+ T lymphocytes from healthy donors are compromised in their proliferative response to a polyclonal stimulus (ConA) if they are preincubated with DENV-2 in vitro. Previously, impairment of T-lymphocyte proliferation had only been observed in dengue patients but this was attributed to a defect in antigen-presenting cells rather than to an intrinsic defect on Tlymphocytes [31].

In addition, we show that DENV-2 preincubated $\mathrm{T}$ lymphocytes also fail to synthesize IL-2 and to express IL$2 \mathrm{Ra}$ (CD25) in response to ConA or PMA/ionomycin, respectively. This is in keeping with the previous observation that $\mathrm{T}$ cells that are deficient in IL-2 synthesis and IL-2R expression, fail to proliferate in response to adequate stimulation, as in the case of $\mathrm{HIV}-1$, hepatitis $\mathrm{C}$ and herpesvirus infections [44, 45, 50, 51].

In order to examine the possible mechanism(s) that could account for the observed DENV-2-induced functional defects on T lymphocytes, we analyzed the nuclear 


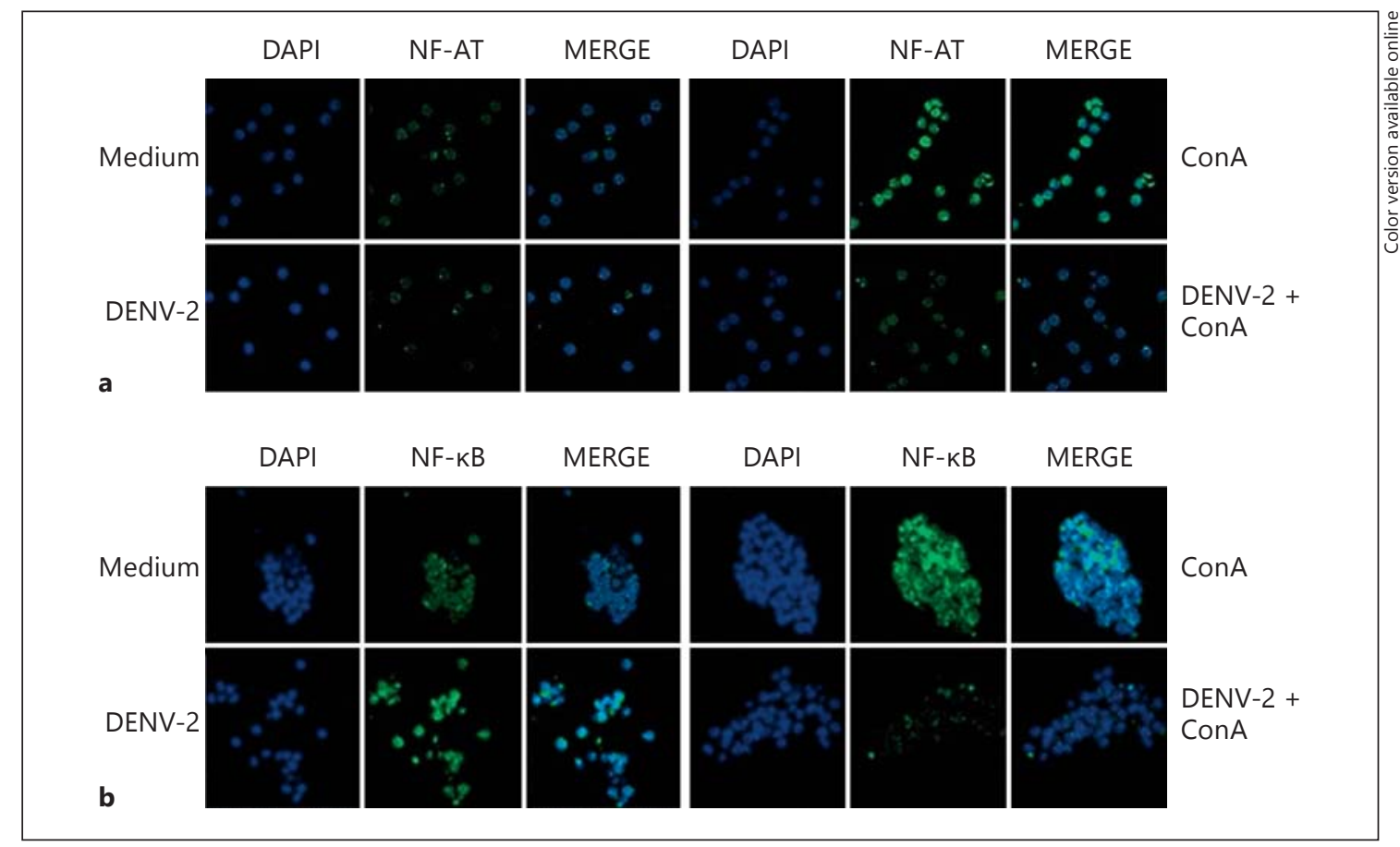

Fig. 4. DENV-2 impairs activation of NF-AT and NF- $\kappa$ B. Freshly isolated T lymphocytes were cultured in Lab-Tek chambers and treated as indicated. Cells were fixed, permeabilized and stained with the corresponding anti-NF-AT or anti-p65 NF- $\kappa$ B antibodies followed by fluorochrome-labelled secondary antibodies. Cells were mounted with DAPI-Vectashield and then analyzed by confocal microscopy for intracellular localization of (a) NF-AT and (b) NF- $\mathrm{KB}$ in cells treated with DENV-2. Images show representative results from multiple microscope fields out of 2-4 independent experiments.
Fig. 5. DENV-2 does not impair T-lymphocyte calcium mobilization. Freshly isolated T lymphocytes were cultured in medium alone or in the presence of DENV-2 for $2 \mathrm{~h}$, labelled with the calcium indicator Fluo-4 and then washed and suspended in culture medium containing $2 \mathrm{mM} \mathrm{CaCl}_{2}$. Mean fluorescence intensity as indicative of intracellular calcium concentration was recorded for $30 \mathrm{~s}$ by flow cytometry and at this time ConA was added and intracellular calcium concentration was further recorded for approximately $400 \mathrm{~s}$. a Calcium flux (representative raw data) in response to ConA stimulation when sucrose-purified DENV-2 + ConA was used. b FlowJo data analysis of calcium flux raw data. Representative experiments out of three independent experiments.

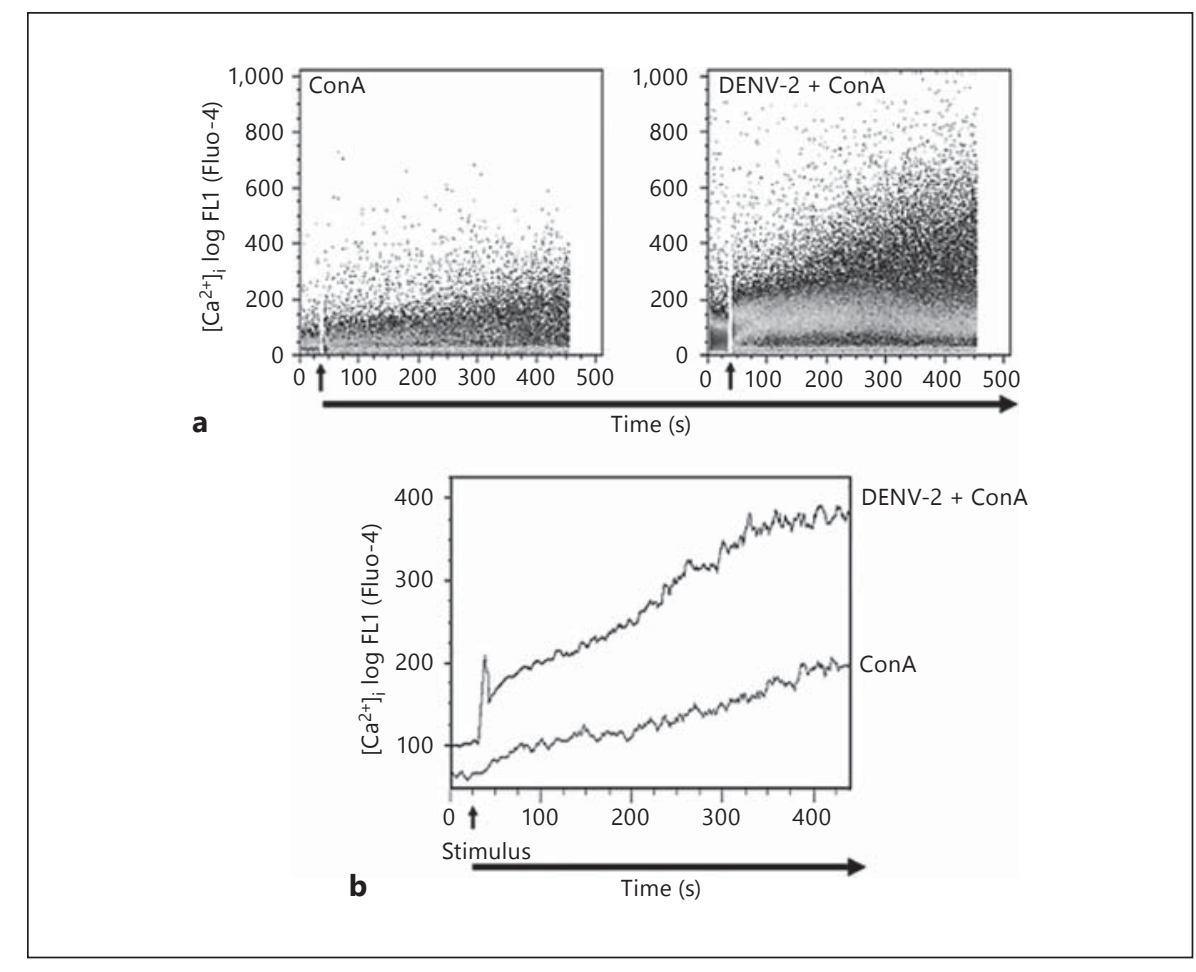




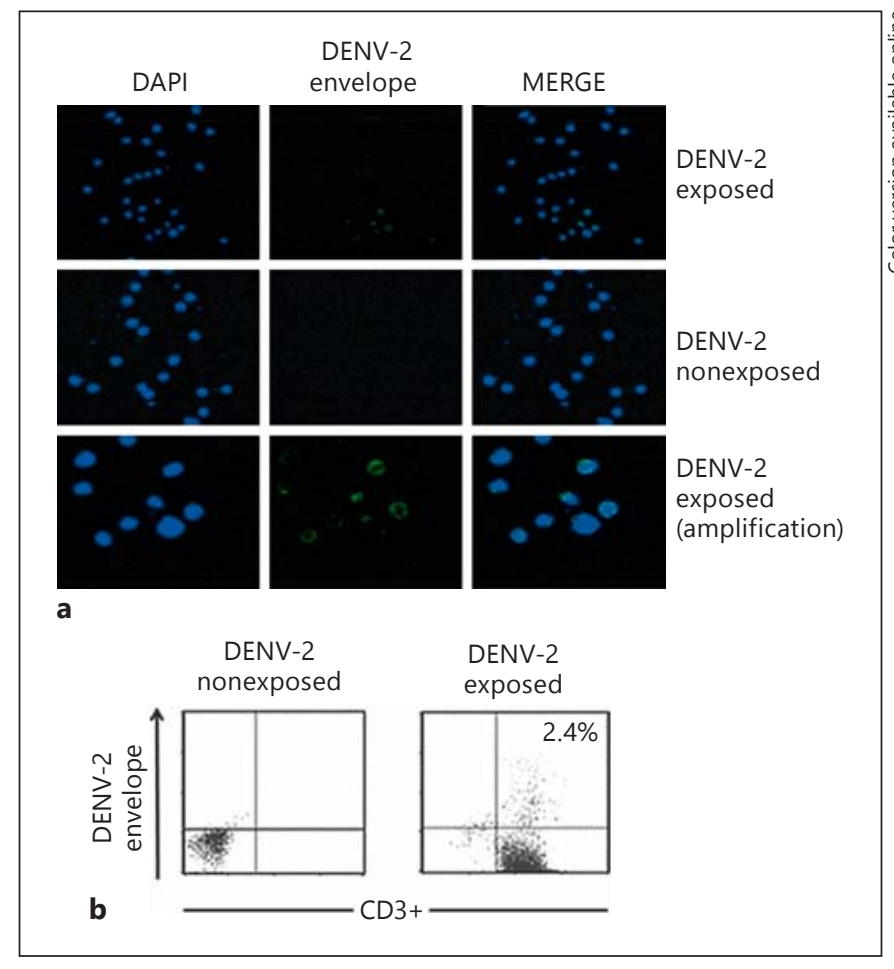

Fig. 6. DENV-2 attachment to T lymphocytes. Freshly isolated T lymphocytes were cultured in Lab-Tek chambers in medium alone or in the presence of DENV-2 at a MOI of 1 for $2 \mathrm{~h}$, cells were then washed, fixed with $1 \%$ paraformaldehyde, washed again and stained with anti-E (DENV envelope protein) mouse moAb, followed by anti-mouse IgG-FITC. Cells were mounted with DAPIVectashield and then analyzed by confocal microscopy. In addition, T lymphocytes cultured in medium alone or in the presence of DENV-2 at a MOI of 1 for $2 \mathrm{~h}$ were stained for DENV-2 envelope protein (anti-E moAb + anti-mouse IgG-FITC) and for CD3 (anti-CD3-PE). a Confocal microscope images showing binding of DENV-2 to T lymphocytes. b Percentage of T lymphocytes with attached DENV-2 as assessed by flow cytometry. Results are representative from three independent experiments.

translocation of NF-AT and NF- $\kappa \mathrm{B}$ which are transcription factors required for IL-2 and IL-2Ra synthesis and expression $[52,53]$. Our results showed that the nuclear translocation of NF-AT and NF- $\kappa \mathrm{B}$ was reduced in DENV-2 pretreated Tlymphocytes as compared with the nuclear translocation in T lymphocytes stimulated with ConA in the absence of DENV-2 (fig. 4).

Nuclear translocation of NF-AT is largely dependent on intracytoplasmic calcium concentration [48, 49]. Therefore, we evaluated the calcium flux in response to ConA in order to determine if the observed DENV-2-induced impairment in NF-AT activation was related to impaired calcium flux. We found that DENV-2 did not impair calcium flux over a time frame of about $400 \mathrm{~s}$ post-

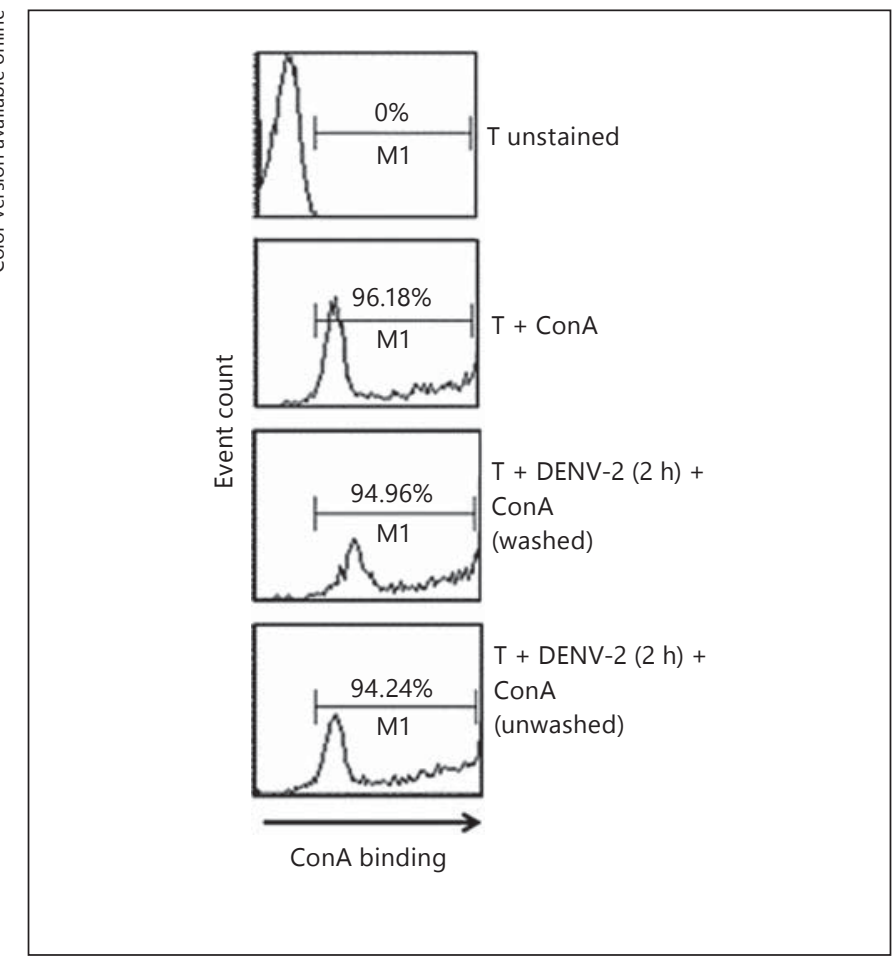

Fig. 7. Binding of ConA to T lymphocytes is not impaired by preexposure to DENV-2. Freshly isolated T lymphocytes were incubated for $2 \mathrm{~h}$ in medium alone or in the presence of sucrosepurified DENV-2 at a MOI of 1, cells were then washed or left unwashed and stained with ConA-biotin, followed by Streptavidin-FITC. After washing, cells were fixed with $1 \%$ paraformaldehyde in PBS and ConA binding was assessed by flow cytometry. Histograms depict the percentage of ConA-positive cells. Results are representative of three independent experiments.

stimulation (fig. 5); on the contrary, a small increase in intracytoplasmic calcium concentration was observed in DENV-2/ConA- as compared to ConA-stimulated T cells.

To the best of our knowledge, calcium fluxes in T lymphocytes exposed to DENV-2 had not been previously explored. However, it has been shown, for instance, that the expression of the Epstein-Barr virus latency-associated membrane protein LMP2A in B lymphocytes diminishes the calcium influx in response to anti-IgM, antiMHC class II, or anti-CD19 treatments [54], and that herpesvirus $\mathrm{K} 7$ protein increases the intracellular calcium concentration by interacting with calcium-modulating cyclophilin ligand [55]. More recently, DENV-2 capsid (C) protein has also been shown to interact with calciummodulating cyclophilin ligand, thus subverting apoptosis in Huh-7 DENV-2-infected cells [56]. Thus it seems that DENV-2 modifies cell responses by modulating calcium flux, the mechanism of which remains to be analyzed. 
There is evidence that Tlymphocytes are not infected by DENV, so we wondered how DENV-2 pre-exposure could impair the activation-induced proliferation as well as disrupting associated signalling pathways. In trying to address this we assessed whether DENV-2 is capable of attaching to the cell membrane of T lymphocytes and found that it does, although at a given time only about $2-3 \%$ of $\mathrm{T}$ lymphocytes harbor attached viral particles, as assessed by confocal microscopy and flow cytometry (fig. 6). Experiments carried out with UVirradiated DENV-2 virus particles showed that they performed just as well as fully active DENV-2 (data not shown), thus suggesting that a receptor engagement mechanism rather than productive infection may be responsible for the observed DENV-2 biological effects on T lymphocytes.

Since only about $2-3 \%$ of T lymphocytes were found to harbor DENV-2, whereas T-lymphocyte proliferation, IL-2R $\alpha$ expression and IL-2 synthesis were reduced by about $50 \%$, we are tempted to speculate that DENV-2 binds with low affinity and high off-rate to a still unknown receptor on T lymphocytes, that this interaction is enough to impair T-lymphocyte activation and that as DENV-2 is released from one such receptor, it is able to sequentially engage the receptors of nearby $\mathrm{T}$ lymphocytes, in analogy with the serial engagement model as proposed for the $\mathrm{T}$-cell receptor triggering by peptideMHC complexes [57, 58].

Finally, since it has been shown that ConA has affinity for DENV-2 envelope (E) protein [59], assessment of
ConA binding to purified T lymphocytes in the presence of DENV-2 was carried out. Results (fig. 7) ruled out the possibility that, under the different culture conditions described here, DENV-2 interferes with ConA binding to these cells and therefore we conclude that the inhibitory effects of DENV-2 on T lymphocytes take place downstream of ConA engagement to its cognate receptor on T-lymphocyte cell membrane. Moreover, IL-2Ra expression was assessed by stimulating $\mathrm{T}$ lymphocytes with PMA/ionomycin, which in preliminary experiments showed to induce higher levels of expression than ConA. DENV-2 was therefore capable of impairing ConA- as well as PMA/ionomycin-induced responses.

In conclusion, we have shown here that exposure of CD4+ and CD8+ T lymphocytes from healthy donors to DENV-2 impairs the ConA-induced proliferation, and that this effect is dependent on impairment of the synthesis of IL-2 and the expression of IL-2Ra by interfering with the activation of NF-AT and NF- $\mathrm{BB}$ downstream of calcium mobilization.

\section{Acknowledgements}

The authors thank the staff of the Women's Hospital Blood Bank (Mexico City) for providing healthy donor buffy coats, and the Immunology postgraduate program core lab (ENCB-IPN) for confocal microscopy and flow cytometry facilities. This work was financed in part by SIP-20130972 grant. CJFM was supported by a CONACYT studentship. FJSG, ORE, RST, and MMBMA are EDI/ COFAA/SNI fellows.

\section{References}

1 World Health Organization: Dengue and Dengue Haemorrhagic Fever. Fact Sheet No 117. Geneva, WHO, 2009.

2 Srikiatkhachorn A, Green S: Markers of dengue disease severity. Curr Top Microbiol Immunol 2010;338:67-82.

3 Hombach J: Vaccine against dengue: a review of current candidate vaccines at advanced development stages. Rev Panam Salud Publica 2007;21:254-260.

4 Rothman AL: Cellular immunology of sequential dengue virus infection and its role in disease pathogenesis. Curr Top Microbiol Immunol 2010;338:83-98.

5 Halstead SB, Chow J, Marchette NJ: Immunologic enhancement of dengue virus replication. Nat New Biol 1973;243:24-26.

-6 Dejnirattisai W, Jumnainsong A, Onsirisakul N, Fitton P, Vasanawathana S, Limpitikul W, Puttikhunt C, Edwards C, Duangchinda T, Supasa S, Chawansuntati K, Malasit P, Mon- gkolsapaya J, Screaton G: Cross-reacting antibodies enhance dengue virus infection in human. Science 2010;328:745-748.

7 Chareonsirisuthigul T, Kalayanarooj S, Ubol $S$ : Dengue virus (DENV) antibody-dependent enhancement of infection up-regulates the production of anti-inflammatory cytokines, but suppresses anti-DENV free radical and pro-inflammatory cytokine production, in THP-1 cells. J Gen Virol 2007;88:365-375.

-8 Butthep P, Chunhakan S, Yoksan S, Tangnararatchakit K, Chuansumrit A: Alteration of cytokines and chemokine during febrile episodes associated with endothelial cell damage and plasma leakage in dengue hemorrhagic fever. Pediatr Infect Dis 2012;31:e232-e238.

-9 Chaturvedi UC, Agarwal R, Elbishbishi EA, Mustafa AS: Cytokine cascade in dengue haemorrhagic fever: implications for pathogenesis. FEMS Immunol Med Microbiol 2000;28:183-188.
10 Appanna R, Wang SM, Ponnampalavanar SA, Lum LC, Sekaran SD: Cytokine factor present in dengue patient sera induces alterations of junctional proteins in human endothelial cell. Am J Trop Med Hyg 2012;87:936942 .

11 Avirutnan P, Punyadee N, Noisakran S, Komoltri C, Thiemmeca S, Auethavornanan K, Jairungsri A, Kanlaya R, Tangthawornchaikul N, et al: Vascular leakage in severe dengue virus infections: a potential role for the non-structural viral protein NS1 and complement. J Infect Dis 2006;193:10781088.

12 Malasit P: Complement and dengue haemorrhagic fever/shock syndrome. Southeast Asian J Trop Med Pub Health 1987;18:316320.

13 Luplertlop N, Missé D: MMP cellular response to dengue virus infection-induced vascular leakage. J Infect Dis 2008;67:298-301. 
14 Friberg H, Bashyam H, Toyosaki-Maeda T, Potts JA, Greenough G, Kalayanarooj S, Gibbons R, Nisalak A, Srikiatkhachorn A, Green S, Stephens HA, Rothman AL, Mathew A: Cross-reactivity and expansion of denguespecific $\mathrm{T}$ cell during acute primary and secondary infection in humans. Sci Rep 2011;1: 1-9.

15 Appanna R, Huat TL, Chai LL, Ta LP, Vadivelu J, Devi S: Cross-reactive T-cell responses to the non-structural regions of dengue viruses among dengue fever and dengue haemorrhagic fever patients in Malaysia. Clin Vaccine Immunol 2007;14:969-977.

16 Kurane I, Meager A, Ennis FA: Dengue virusspecific human T-cell clones. Serotype crossreactive proliferation, interferon $-\gamma$ production, and cytotoxic activity. J Exp Med 1989; 170:763-775.

17 Vaughn DW, Green S, Kalayanarooj S, Innis BL, Nimmannitya S, Suntayakorn S, Endy TP, Raengsakulrach B, Rothman AL, Ennis FA, Nisalak A: Dengue viremia titer, antibody response pattern, and virus serotype correlate with disease severity. J Infect Dis 2000;181: 2-9.

18 Martina BE, Koraka P, Osterhaus AD: Dengue virus pathogenesis: an integrated view. Clin Microbiol Rev 2009;22:564-581.

19 Nhan NT, Phuong CX, Kneen R, Wills B, Van My N, Phuong NT, Thien CV, Nga NT, Simpson JA, Solomon T, White NJ, Farrar J: Acute management of dengue shock syndrome: randomized double-blind comparison of intravenous fluid regimens in the first hour. Clin Infect Dis 2001;32:204-213.

20 Kurane I, Matsutani T, Suzuki R, Takasaki T, Kalayanarooj S, Green S, Rothman A, Ennis $\mathrm{F}$ : T-cell responses to dengue virus in human. Trop Med Health 2011;39:45-51.

21 Dong T, Moran E, Vinh Chau N, Simmons C, Luhn K, Peng Y, Wills B, Phuong Dung N, Thi Thu Thao L, Hien TT, McMichael A, Farrar J, Rowland-Jones S: High pro-inflammatory cytokine secretion and loss of high avidity crossreactive cytotoxic $\mathrm{T}$-cells during the course of secondary dengue virus infection. PLoS One 2007;2:e1192.

22 Green S, Rothman A: Immunopathological mechanisms in dengue and dengue hemorrhagic fever. Curr Opin Infect Dis 2006; 19: 429-436.

23 Duangchindaa T, Dejnirattisaia W, Vasanawathanac S, Limpitikuld W, Tangthawornchaikulb N, Malasitb P, Mongkolsapayaa J, Screatona G: Immunodominant T-cell responses to dengue virus NS3 are associated with DHF. Proc Natl Acad Sci USA 2010;107: 16922-16927.

24 Kurane I, Innis BL, Nimmannitya S, Nisalak A, Meager A, Janus J, Ennis FA: Activation of $\mathrm{T}$ lymphocytes in dengue virus infections. High levels of soluble interleukin-2 receptor, soluble CD4, soluble CD8, interleukin-2, and interferon- $\gamma$ in sera of children with dengue. Clin Invest 1991;88: 1473-1480.
25 Mangada MM, Rothman AL: Altered cytokine responses of dengue-specific CD4+ $\mathrm{T}$ cells to heterologous serotypes. J Immunol 2005; 175:2676-2683.

26 Bashyam HS, Green S, Rothman AL: Dengue virus-reactive $\mathrm{CD} 8+\mathrm{T}$ cells display quantitative and qualitative differences in their response to variant epitopes of heterologous viral serotypes. J Immunol 2006; 176:28172824.

27 Imrie A, Meeks J, Gurary A, Sukhbataar M, Kitsutani P, Effler P, Zhao Z: Differential functional avidity of dengue virus-specific T-cell clones for variant peptides representing heterologous and previously encountered serotypes. J Virol 2007;81:1008110091.

28 Chuang V, Wong TY, Leung YH, Ma E, Law YL, Tsang O, Chan KM, Tsang I, Que TL, Yung R, Liu SH: Review of dengue fever cases in Hong Kong during 1998 to 2005. Hong Kong Med J 2008; 14:170-177.

29 Sawasdivorn S, Vibulvattanakit S, Sasavatpakdee $M$, Iamsirithavon S: Efficacy of clinical diagnosis of dengue fever in paediatric age groups as determined by WHO case definition 1997 in Thailand. Dengue Bull 2001;25: 56-64.

-30 Fadilah SA, Sahrir S, Raymond AA, Cheong SK, Aziz JA, Sivagengei K: Quantitation of T-lymphocyte subsets helps to distinguish dengue haemorrhagic fever from classic fever during the acute febrile state. Southeast Asian J Trop Med Public Health 1999;30: 710-717.

-31 Mathew A, Kurane I, Green S, Vaughn DW, Kalayanarooj S, Suntayakorn S, Ennis FA, Rothman AL: Impaired T-cell proliferation in acute dengue infection. J Immunol 1999;162: 5609-5615.

32 Jessie K, Fong MY, Devi Lam SK, Wong KT: Localization of dengue virus in naturally infected human tissues, by immunohistochemistry and in situ hybridization. J Infect Dis 2004;189:1411-1418.

33 O'Sullivan MA, Killen HM: The differentiation state of monocytic cell affects their susceptibility to infection and the effects of infection by dengue virus. J Gen Virol 1994;75: 2387-2392.

-34 Yuan-Chang C, Ching-Shan H, Chun-Nan L, Sui-Yuan C, Chwan-Chen K, Chuan-Liang K: Higher infection of dengue virus serotype in human monocytes of patients with G6PD deficiency. PloS One 2008;3:e1557.

35 Pryor MJ, Carr JM, Hocking H, Davidson AD, Wright PJ: Replication of dengue virus type 2 in human monocyte-derived macrophages: comparisons of isolates and recombinant viruses with substitutions at amino acid 390 in envelope glycoprotein. Am J Trop Med Hyg 2001;65:427-434

36 Moreno-Altamirano MM, Sánchez-García FJ, Muñoz ML: Non-Fc receptor-mediated infection of human macrophages by dengue virus serotype 2. J Gen Virol 2002;83:11231130.
37 Marovich M, Grouard-Vogel G, Louder M, Eller M, Sun W, Wu SJ, Putvatana R, Murphy G, Tassaneetrithep B, Burgess T, Birx D, Hayes C, Schlesinger-Frankel S, Mascola J: Human dendritic cell as targets of dengue virus infection. J Invest Dermatol Symp Proc 2001;6:219-224.

38 Ling-Jun J, Jaang-Jium W, Men-Fang S, Chuan-Liang $\mathrm{K}$, Deh-Ming C, Shou-Wha $\mathrm{H}$, Jenn-Haung L: Infection of human dendritic cell by dengue virus causes cell maturation and cytokine production. J Immunol 2001; 166:1499-1506.

39 Wu SJ, Grouard-Vogel G, Sun W, Mascola JR, Brachtel E, Putvatana R, Louder MK, Filgueira L, Marovich MA, Wong HK, Blauvelt A, Murphy GS, Robb ML, Innes BL, Birx DL, Hayes CG, Frankel SS: Human skin Langerhans' cell are targets of dengue virus infection. Nat Med 2000;6:816-820.

40 Lin YW, Wang KJ, Lei HY, Lin YS, Yeh TM, Liu HS, Liu CC, Chen SH: Virus replication and cytokine production in dengue virus-infected human B lymphocytes. J Virol 2002;76: 12242-12249.

41 Mentor NA, Kurane I: Dengue virus infection of human T lymphocytes. Acta Virol 1997;41: 175-176.

42 Blackley S, Kou Z, Chen H, Quinn M, Rose RC, Schlesinger JJ, Coppage M, Jin X: Primary human splenic macrophages, but not $\mathrm{T}$ or $\mathrm{B}$ cells, are the principal target cells for dengue virus infection in vitro. J Virol 2007;81: 13325-13334.

-43 Kuo Z, Quinn M, Chen H, Rodrigo WW, Rose RC, Schlesinger JJ, Jin X: Monocytes but not $\mathrm{T}$ or $\mathrm{B}$ cells are the principal target cells for dengue virus infection among human peripheral blood mononuclear cells. J Med Virol 2008;80:134-146.

44 Flamand L, Gosselin J, Stedanescu I, Ablashi $\mathrm{D}$, Menezes J: Immunosuppressive effect of human herpesvirus 6 on T-cell functions: suppression of interleukin-2 synthesis and cell proliferation. Blood 1995;85:1263-1271.

45 Sundström S, Ota S, Dimberg L, Masucci M, Bergqvist A: Hepatitis C virus core protein induces an anergic state characterized by decreased Interleukin-2 production and perturbation of mitogen-activated protein kinase responses. J Virol 2005;79:22302239.

46 Malek TR, Castro I: Interleukin-2 receptor signaling: at the interface between tolerance and immunity. Immunity 2010;33:153-165.

47 Quintana A, Griesemer D, Schwarz EC, Hoth M: Calcium-dependent activation of T lymphocytes. Eur J Physiol 2005;450:1-12.

48 Dolmetsch RE, Lewis RS, Goodnow CC, Healy JI: Differential activation of transcription factors induced by $\mathrm{Ca}^{2+}$ response amplitude and duration. Nature 1997;386:855-858

49 Feske S, Rao A, Hogan PG: The $\mathrm{Ca}^{2+}$-calcineurin-NFAT signalling pathway; in Krebs J, Michalak M (eds): Calcium: A Matter of Life or Death, chapt 14. Amsterdam, Elsevier, 2007, pp 365-401. 
50 Bass HZ, Fahey JL, Nishanian P, Detels R, Cumberland W, Kemeny M, Plaeger S: Relation of impaired lymphocyte proliferative function to other major human immunodeficiency virus type 1-induced immunological changes. Clin Diag Lab Immunol 1997;4:6469.

51 Semmo N, Day CL, Ward SM, Lucas M, Harcurt G, Loughry A, Klenerman P: Preferential loss of IL-2-secreting CD4+ T-helper cells in chronic HCV infection. Hepatology 2005; 41: 1019-1028.

52 Schuh K, Twardzik T, Kneitz B, Heyer J, Schimpl A, Serfling E: The interleukin-2 receptor a chain/CD25 promoter is a target for nuclear factor of activated T cells. J Exp Med 1998;188:1369-1373.
53 Serfling E, Avots A, Neumann M: The architecture of the interleukin-2 promoter: a reflection of T-lymphocyte activation. Biochim Biophys Acta 1995;1263:181-200.

54 Miller CL, Longnecker R, Kieff E: EpsteinBarr virus latent membrane protein $2 \mathrm{~A}$ blocks calcium mobilization in B lymphocytes. J Virol 1993;67:3087-3094.

55 Feng P, Park J, Lee BS, Lee SH, Bram RJ, Jung JU: Kaposi's sarcoma-associated herpesvirus mitochondrial $\mathrm{K} 7$ protein targets a cellular calcium-modulating cyclophilin ligand to modulate intracellular calcium concentration and inhibit apoptosis. J Virol 2002;76:1149111504.
56 Li J, Huang R, Liao W, Chen Z, Zhang S, Huang R: Dengue virus utilizes calcium modulating cyclophilin-binding ligand to subvert apoptosis. Biochem Biophys Res Commun 2012;418:622-627.

57 Valitutti S, Muller S, Cella M, Padovan E, Lanzavecchia A: Serial triggering of many T-cell receptors by a few peptide-MHC complexes. Nature 1995;375:148-151.

58 Valitutti S: The serial engagement model 17 years after: from TCR triggering to immunotherapy. Front Immunol 2012;3:272.

59 Stohlman SA, Eylar OR, Wisseman CL Jr: Isolation of the dengue virus envelope glycoprotein from membranes of infected cells by concanavalin A affinity chromatography. J Virol 1976;18:132-140. 